\title{
The timing of multiple retrieval events can alter GluR1 phosphorylation and the requirement for protein synthesis in fear memory reconsolidation
}

\author{
Timothy J. Jarome, Janine L. Kwapis, Craig T. Werner, Ryan G. Parsons, Georgette \\ M. Gafford, and Fred J. Helmstetter ${ }^{1}$ \\ Psychology Department, University of Wisconsin-Milwaukee, Milwaukee, Wisconsin 53201, USA
}

\begin{abstract}
Numerous studies have indicated that maintaining a fear memory after retrieval requires de novo protein synthesis. However, no study to date has examined how the temporal dynamics of repeated retrieval events affect this protein synthesis requirement. The present study varied the timing of a second retrieval of an established auditory fear memory and followed this second retrieval with infusions of the protein synthesis inhibitor anisomycin (ANI) into the basolateral amygdala. Results indicated that the memory-impairing effects of ANI were not observed when the second retrieval occurred soon after the first (within $1 \mathrm{~h}$ ), and that the inhibitor gradually regained effectiveness as the retrieval episodes were spaced further apart. Additionally, if the second of the closely timed retrievals was omitted prior to ANI infusions, long-term memory deficits were observed, suggesting that the altered effectiveness of ANI was due specifically to the second retrieval event. Further experiments revealed that the second retrieval was not associated with a change in Zif268 protein expression but did produce a rapid and persistent dephosphorylation of GluR1 receptors at Ser845, an AMPAR trafficking site known to regulate the stability of GluR2 lacking AMPARs, which have been shown to be important in memory updating. This suggests that the precise timing of multiple CS presentations during the reconsolidation window may affect the destabilization state of the memory trace.
\end{abstract}

[Supplemental material is available for this article.]

The amygdala is a critical site for the formation and stability of long-term fear memories (Fanselow and LeDoux 1999). Once acquired, fear memories go through a stabilization process that depends upon new gene transcription, de novo protein synthesis, and ubiquitin-proteasome mediated protein degradation, a process referred to as memory consolidation (Bailey et al. 1999; McGaugh 2000; Schafe and LeDoux 2000; Parsons et al. 2006a; Jarome et al. 2011). It has been shown that these once stable memories can again become labile and sensitive to the effects of protein synthesis inhibitors following a brief, nonreinforced reminder event (Nader et al. 2000; Parsons et al. 2006b). This result suggests that initially consolidated memories "destabilize" following brief reminders and need de novo protein translation in order to "restabilize," a process collectively referred to as reconsolidation (Lee 2008).

While a number of studies have suggested a potential role for a variety of immediate early genes and signal-transduction pathways in memory reconsolidation (Duvarci et al. 2005; Merlo et al. 2005; Tronson et al. 2006; Boccia et al. 2007; Tronson and Taylor 2007), very little is known about the temporal dynamics of the reconsolidation process. Some recent evidence suggests that retrieval of a young memory results in memory strengthening, while retrieval of an older memory results in memory extinction (Inda et al. 2011). Interestingly, the underlying amygdala physiology for recent memories is different from that of older memories (Clem and Huganir 2010). For example, fear conditioning results in a time-dependent switch from GluR2 containing

\footnotetext{
${ }^{1}$ Corresponding author

E-mail fjh@uwm.edu

Article is online at http://www.learnmem.org/cgi/doi/10.1101/Im.024901.111.
}

AMPA receptors to GluR2 lacking AMPA receptors in the amygdala. Expression of these calcium-permeable AMPA receptors (CPAMPARs) peaks $24 \mathrm{~h}$ after conditioning and subsides by $1 \mathrm{wk}$. This change in AMPAR dynamics was shown to be important for the retrieval-induced erasure of fear memory following extinction training (Monfils et al. 2009). However, how the presence of these CP-AMPARs changes the dynamics of how a memory reconsolidates currently remains unknown.

Protein synthesis is known to be important in the amygdala immediately, but not $6 \mathrm{~h}$ after memory retrieval (Nader et al. 2000). Additionally, retrieval of a recent memory requires new protein synthesis even after multiple retrievals across several days (Inda et al. 2011). However, it currently remains unclear how varying the timing of the second retrieval relative to the first may change the dynamics of the reconsolidation process. In the present study, we varied the timing of the second of two retrieval events, followed by infusions of a protein synthesis inhibitor into the amygdala. We found that a second retrieval event could alter the protein synthesis requirement for the first retrieval event when presented within $1 \mathrm{~h}$ of the first CS retrieval, and this altered protein-synthesis requirement was related to changes in the phosphorylation of synaptic GluR1 receptors.

\section{Results}

Closely timed retrievals alter the requirement for protein synthesis

In the first experiment, we examined how varying the timing between two retrieval events affects the requirement for protein synthesis during the reconsolidation process (Fig. 1A). All animals 

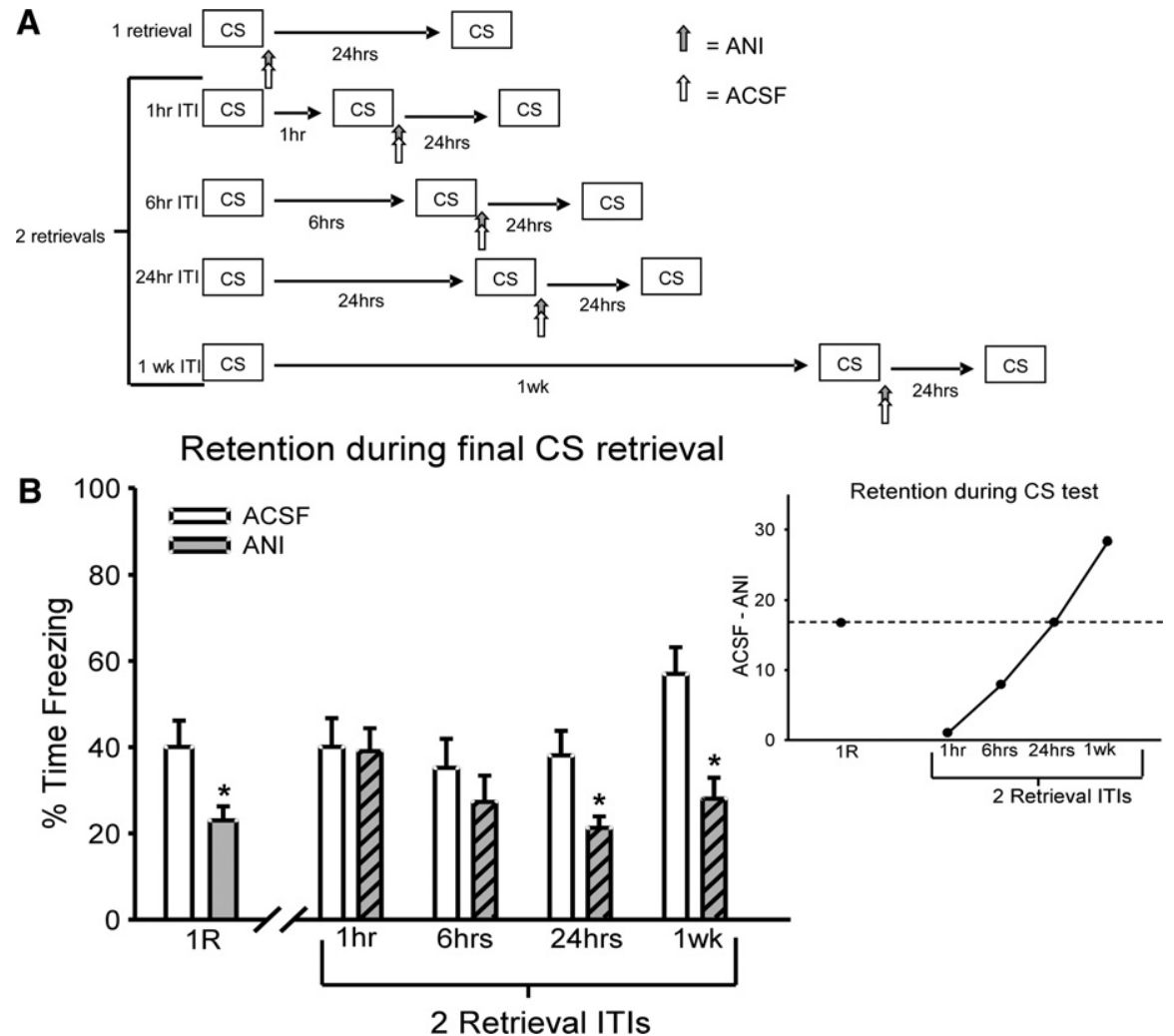

Figure 1. Multiple retrieval events can alter the requirement for protein synthesis in reconsolidation. (A) Procedure for the five conditions that varied the number and timing of retrievals. In all conditions, one group received anisomcyin (ANI) and another received ACSF as a control. (B) ANI produces longterm impairments when given immediately following a single retrieval $(A C S F=15, A N I=14)$, or a second retrieval that is spaced $24 \mathrm{~h}(\mathrm{ACSF}=17, \mathrm{ANI}=16)$ or $1 \mathrm{wk}(\mathrm{ACSF}=9, \mathrm{ANI}=9)$ apart from the first retrieval event. However, no long-term deficits are noticed when the same drug is given immediately following a second retrieval that was spaced only $1 \mathrm{~h}(\mathrm{ACSF}=15, \mathrm{ANI}=15)$ or $6 \mathrm{~h}(\mathrm{ACSF}=10$, $\mathrm{ANI}=11$ ) after the first retrieval event. Outset shows the deficit observed in animals receiving ANI following retrieval relative to animals receiving ACSF. As the timing of the second retrieval relative to first increases, the ANI-induced memory impairment increases. $\left(^{*}\right) P<0.05$ from ACSF control.

the first, no deficits in long-term memory were noted with ANI. Additionally, when retrieval sessions were spaced $24 \mathrm{~h}$ $\left(F_{(1,31)}=6.753, \quad P=0.014\right) \quad$ or $1 \quad \mathrm{wk}$ $\left(F_{(1,18)}=14.286, P=0.001\right)$ apart, impairments in long-term memory would result. This suggests that the protein synthesis requirement was altered only when a second retrieval was given shortly after the first, and that both the presentation of the retrieval and its timing relative to the first retrieval were key factors in this altered protein synthesis requirement. Consistent with this, when two retrievals are spaced only $1 \mathrm{~h}$ apart, the animals that received ANI look identical to those that received control infusions of ACSF (Fig. 1B). This result suggests that the addition of a second retrieval event during the reconsolidation process initiated by first retrieval alters the requirement of protein synthesis for the memory trace.

One explanation for the altered protein synthesis requirement following the second of two closely timed retrieval events is that that the second retrieval occurred during an ANI insensitive period following the initial retrieval (Kim et al. 2010). The possibility exists that the null result obtained with ANI in the 1-h spaced condition was due to the ineffectiveness of the inhibitor at this time point. To test this idea, animals were infused with ANI 67 min after an isolated retrieval event (Supplemental Fig. S2). Results indicated that the infusion of ANI produced long-term memory deficits on a later test $\left(F_{(1,11)}=9.583, P=\right.$ $0.01)$. This result suggests that the alteration in the requirement for protein synthesis following the second of two

were implanted with chronic cannulae aimed at the basolateral amygdala (BLA) (Supplemental Fig. S1) and were initially trained with four pairings of an auditory cue that coterminated with a foot shock. Twenty-four hours after acquisition, all animals were given either one or two retrieval sessions. If an animal received two retrievals, the second was given 1,6 , or $24 \mathrm{~h}$, or $1 \mathrm{wk}$ after the first retrieval. The second retrieval event was followed by local infusions of the protein synthesis inhibitor anisomycin (ANI) into the amygdala. Results indicated that the susceptibility of the retrieved memory to protein synthesis inhibition was altered when the second retrieval occurred soon after the first (Fig. 1B). An ANOVA was conducted with DRUG (ANI or ACSF) and CONDITION (1R, 2R 1 h, 2R 6 h, 2R 24 h, 2R 1 wk) as independent variables. There was a main effect for DRUG $\left(F_{(1,123)}=15.934, P<\right.$ $0.001)$ but not for CONDITION $\left(F_{(4,123)}=2.117, P=0.083\right)$. Additionally, there was no DRUG $\times$ CONDITION interaction $\left(F_{(4,123)}=1.627, P=0.172\right)$. In order to determine in which conditions ANI was effective at producing long-term memory deficits, the data was split by CONDITION and ANOVAs were conducted for DRUG. Results indicated that when protein synthesis was blocked following a single retrieval, long-term memory impairments resulted $\left(F_{(1,27)}=5.014, P=0.034\right)$. However, if the animals were given a second retrieval event that occurred only $1 \mathrm{~h}$ $\left(F_{(1,28)}=0.014, P=0.906\right)$ or $6 \mathrm{~h}\left(F_{(1,19)}=0.763, P=0.393\right)$ after closely timed retrievals is specific to the second activation of the memory.

\section{Closely timed retrievals do not alter existing Zif268 protein expression}

In the first experiment, we found that the requirement for protein synthesis was altered following the second of two closely timed retrieval events. To see whether the second retrieval event also altered other components of the reconsolidation process, we examined the expression of the immediate early gene product Zif268, a known regulator of synaptic plasticity that may relate to a reconsolidation-specific mechanism (Lee et al. 2004; Lee 2008). To see whether there were alterations in Zif268 protein expression, we sacrificed animals at various time points following retrieval for protein quantification (Fig. 2A). Since increases in zif268 gene expression have been reported 30 min after retrieval (Hall et al. 2001), we first compared its expression at this time following either a single or a second retrieval. Additionally, to control for the temporal pattern of protein expression following an isolated retrieval, we also examined Zif268 expression $97 \mathrm{~min}$ after a single retrieval (Fig. 2B). We found a significant effect for CONDITION $\left(F_{(3,35)}=2.821, P=0.053\right)$. Fisher LSD post hoc showed that while there was a significant increase in Zif268 protein expression $30 \mathrm{~min}$ 

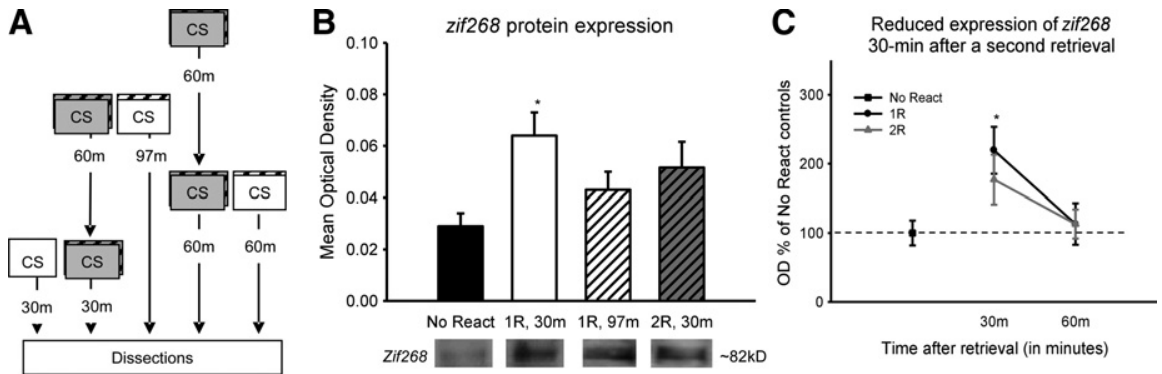

Figure 2. A second closely timed retrieval does not alter existing Zif268 protein expression. (A) Procedure for the conditions that varied the number of retrievals and time until sacrifice following the final retrieval event. (B) Following a single retrieval, Zif268 protein expression is significantly increased in the amygdala at $30 \mathrm{~min}(n=11)$ relative to no retrieval controls $(n=9)$. However, $30 \mathrm{~min}$ after a second retrieval $(n=10)$, which is $97 \mathrm{~min}$ after a single retrieval, there is only a moderate increase in Zif268 protein relative to no retrieval controls, and this is comparable to Zif268 expression observed 97 min after a single retrieval event $(n=9)$. (C) Following a single retrieval, Zif268 protein is significantly higher than controls at $30 \mathrm{~min}$ and subsides by $60 \mathrm{~min}(n=10)$, while following a second retrieval event the increase at $30 \mathrm{~min}$ is impaired and not significantly higher than controls, but shows a normal reduction at $\left.60 \mathrm{~min}(n=10) .{ }^{*}\right) P<0.05$ from no retrieval controls.

after a single retrieval $(P=0.007)$, only a moderate increase was noticed following the second retrieval $(P=0.089)$. Additionally, expression following the second retrieval was comparable to that noticed $97 \mathrm{~min}$ following a single retrieval $(P=0.557)$, suggesting that the second retrieval did not alter the Zif268 expression pattern that was initiated by the first retrieval.

To ensure that there was not a delayed increase in Zif268 protein following a second retrieval, we next examined its expression for $1 \mathrm{~h}$ following either a single or a second retrieval (Fig. 2C). Results indicated a main effect for CONDITION $\left(F_{(4,44)}=3.037\right.$, $P=0.027)$. Fisher LSD post hoc tests indicated that Zif 268 protein expression increased relative to controls $30 \mathrm{~min}$ following retrieval $(P=0.007)$ and returned to baseline levels by $60 \mathrm{~min}(P=$ $0.759)$. Though there was only a marginal increase in protein expression $30 \mathrm{~min}$ after a second retrieval $(P=0.089)$, it returned to baseline levels by $60 \mathrm{~min}(P=0.758)$ and did not differ from the normal pattern noticed following a single retrieval $(P=0.992)$. Collectively, these results suggest that while Zif268 protein expression is increased $30 \mathrm{~min}$ after retrieval and has an additional moderate increase at $90 \mathrm{~min}$, the second retrieval given $1 \mathrm{~h}$ after the first does not change this normal expression pattern. This indicates that expression of Zif268 was not altered following the second retrieval, but rather mirrored the temporal pattern normally observed following a single retrieval event (Supplemental Figs. S3, S4). Collectively, these results suggest that the change in the protein synthesis requirement was not likely due to a change in Zif268 expression following the second retrieval event.

\section{Rapid dephosphorylation of synaptic GluRI(Ser845) following closely timed retrievals}

Fear conditioning induces a temporally limited change in AMPAR dynamics in the amygdala $24 \mathrm{~h}$ after conditioning, which persists for $<1 \mathrm{wk}$ (Clem and Huganir 2010). In the present series of experiments, all CS retrieval events were presented, while the presence of $\mathrm{CP}$ AMPARs was increased in the amygdala. trieval controls.
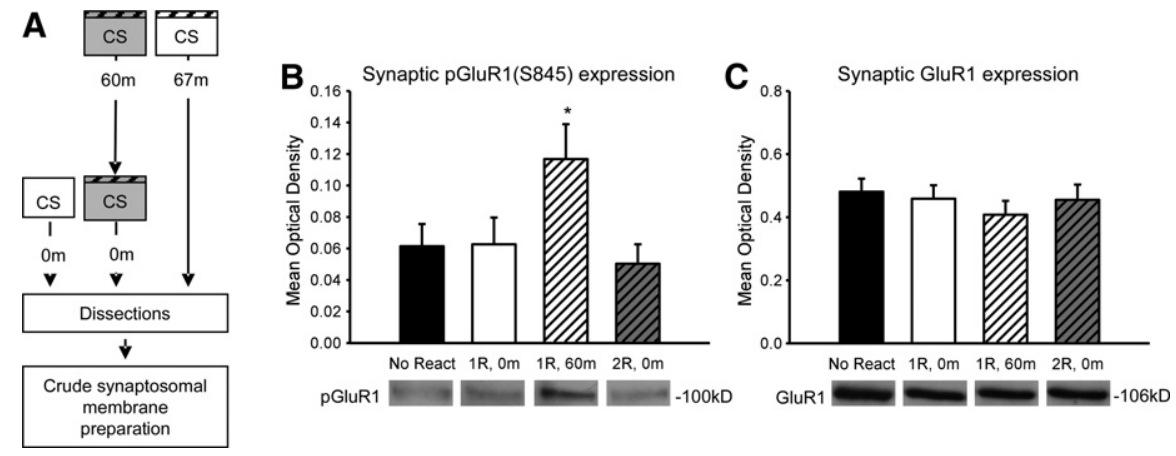

Figure 3. A second closely timed retrieval results in rapid dephosphorylation of synaptic GluR1(Ser845). (A) Procedure for the conditions that varied the number of retrievals and time until sacrifice following the final retrieval event. Crude synaptosomal membrane fractions were then collected. (B) Synaptic GluR1(Ser845) phosphorylation is significantly increased at $60 \mathrm{~min}(n=10)$, but not immediately $(n=9)$ after retrieval relative to no retrieval controls $(n=7)$. The presentation of a second retrieval $1 \mathrm{~h}$ after the first $(n=10)$ results in a rapid dephosphorylation of synaptic GluR1(Ser845). (C) There were no significant differences in total synaptic GluR1 expression. ( $\left.{ }^{*}\right) P<0.05$ from no re- 
retrieval, the addition of a second CS $1 \mathrm{~h}$ after the first rapidly produces a complete dephosphorylation of GluR1(Ser845). Since the increases in GluR1 were observed $60 \mathrm{~min}$, but not immediately after a single retrieval event, it is possible that the dephosphorylation following the second retrieval reversed with time. Additionally, if the dephosphorylation of GluR1 is related to the altered protein synthesis requirement we observed in our first experiment, then spacing retrievals $24 \mathrm{~h}$ or more apart, conditions which were sensitive to protein-synthesis blockade, should not reduce GluR1 phosphorylation. In order to test these ideas, we collected amygdala synaptosomal membrane fractions $60 \mathrm{~min}$ after a second retrieval event that occurred either 1 or $24 \mathrm{~h}$ after the first CS retrieval, and processed them for quantitative protein assays (Fig. 4A). We found a main effect for CONDITION $\left(F_{(2,23)}=\right.$ 3.679, $P=0.041$ ) (Fig. 4B). Fisher LSD post hoc tests revealed that while GluR1(Ser845) phosphorylation was not different from no retrieval controls $60 \mathrm{~min}$ after a second retrieval event that occurred $1 \mathrm{~h}$ after the first $(P=0.958)$, it was significantly higher than both no retrieval controls $(P=0.033)$ and the closely timed retrieval group $(P=0.025)$ when the retrieval events were spaced $24 \mathrm{~h}$ apart. This suggests that the dephosphorylation of GluR1(Ser845) following the second of two closely timed retrievals is persistent and specific to the close spacing of the retrieval events. Additionally, there was not a main effect for total GluR1 levels $\left(F_{(2,24)}=1.206, P=0.317\right)$ (Fig. 4C) or $\beta$-actin $\left(F_{(1,25)}=2.158, P=0.137\right)$ (Supplemental Fig. S7). Collectively, these results suggest that the altered protein synthesis requirement following the second of two closely timed retrievals is related to a persistent dephosphorylation of GluR1(Ser845) and when retrievals are spaced $24 \mathrm{~h}$ or more apart, both GluR1(Ser845) phosphorylation and the requirement for protein synthesis returns.

\section{Discussion}

The temporal dynamics of how a second CS presentation can interact with the reconsolidation process following initial memory retrieval are largely unexplored. Additionally, it currently is unclear whether the changes in AMPA receptor dynamics in the amygdala shortly after fear conditioning can potentially influence how a memory reconsolidates. Our study provides the first evidence that the timing of repeated retrievals can alter the wellestablished requirement for protein synthesis in the amygdala (TJ Jarome, JL Karbowski (Kwapis), and FJ Helmstetter, pers. comm.). The second retrieval did not alter Zif268 protein expression, but the altered protein synthesis requirement was related to
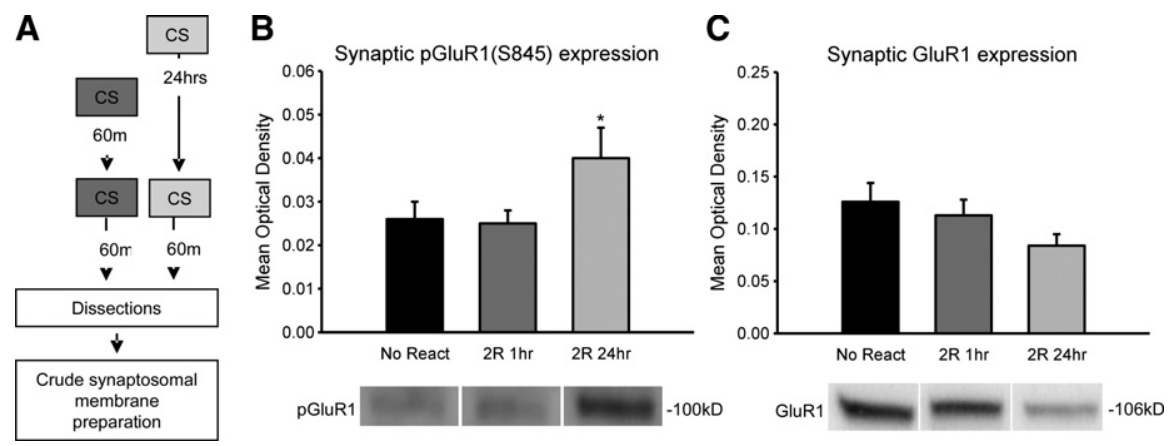

Figure 4. Closely timed, but not spaced retrieval events produce a persistent dephosphorylation of synaptic GluR1(Ser845). (A) Procedure for the conditions that varied the timing of two retrievals. Crude synaptosomal membrane fractions were then collected. (B) Synaptic GluR1(Ser845) phosphorylation is significantly increased 60 min after a second retrieval that occurs $24 \mathrm{~h}(n=9)$, but not $1 \mathrm{~h}$ $(n=9)$, after the first relative to no retrieval controls $(n=8)$. (C) There were no significant differences in total GluR1 expression. $\left(^{*}\right) P<0.05$ from no retrieval controls. a dephosphorylation of synaptic GluR1(Ser845) receptors, a mechanism which was active when protein synthesis inhibitors were effective at disrupting long-term memory. The change in GluR1 phosphorylation, at a site that controls the stability of CP-AMPARs, suggests a potential involvement of the altered amygdala physiology that is present within $1 \mathrm{wk}$ of the initial conditioning (Clem and Huganir 2010). Collectively, these results suggest that closely timed retrieval events can change how the reconsolidation process progresses.

One interpretation for the altered effectiveness of ANI following the second of two closely timed retrievals is that the inhibitor was given at a time following the initial retrieval which is insensitive to protein synthesis inhibition (Kim et al. 2010). Our results suggest that this is not the case. When ANI was given in a similar procedure, but with the second retrieval omitted, persistent long-term memory impairments resulted. This finding suggests that protein synthesis inhibitors are normally effective when administered $67 \mathrm{~min}$ after an isolated retrieval event. Based on this result, the alteration in the effectiveness of ANI was not due to it being administered during a protein synthesis inhibitor insensitive period, but rather was due specifically to the presentation of the second retrieval.

Since a single retrieval increases the need for new protein synthesis, it may be possible that the addition of a second retrieval further enhances this protein synthesis process, so that anisomcyin infusions fail to disrupt memory. While we cannot rule out this interpretation, some evidence suggests that protein synthesis likely was not enhanced as a result of the second retrieval. For example, increases in protein synthesis following retrieval are believed to be necessary for memory updating and storage, so if protein synthesis was further enhanced as a result of the second closely timed retrieval, we would expect to see at least some increase in performance in vehicle-infused controls (Tronson et al. 2006). However, our ACSF control animals show equivalent performance to the ANI animals on the long-term memory test and are no different from any of the other control groups (Fig. 1B), suggesting that memory was not enhanced. Additionally, anisomycin could not disrupt memory when it was administered after a second retrieval that was given $6 \mathrm{~h}$ after the first. By $6 \mathrm{~h}$ after retrieval, the protein synthesis process is largely complete (Nader et al. 2000). The fact that anisomycin still could not disrupt memory at this time suggests that the altered requirement for protein synthesis in the closely timed retrieval condition may not have been due to an additional enhancement in protein synthesis. Also, protein degradation has been shown to underlie the requirement for protein synthesis in the amygdala following memory retrieval and learning-induced increases in protein degradation mirror increased translational regulation (Jarome et al. 2011). However, we did not observe further increases in protein degradation following the second of two closely timed retrievals (data not shown), suggesting that the protein synthesis process that is related to increased protein degradation may not have been altered. Furthermore, the dosage/volume of anisomycin given in the present study produces $>60 \%$ reduction in leucine incorporation in our hands (Parsons et al. 2006b), suggesting that even if protein synthesis were further enhanced following the second retrieval, memory would have to somehow stabilize despite a significant reduction in overall protein synthesis. However, without a direct 
measure of new protein synthesis, we cannot rule out the possibility that the second retrieval did further enhance protein synthesis.

Recent evidence suggests that retrieving a young memory multiple times over several days can lead to a strengthening of the memory trace (Inda et al. 2011). This memory strengthening was evident through a reduced susceptibility to post retrieval administration of protein synthesis inhibitors. The possibility exists that the altered protein synthesis requirement in the present study may be due to memory strengthening that occurred following the second CS retrieval. However, our results do not support such an interpretation. While the second retrieval did alter the effectiveness of protein synthesis inhibitors at disrupting long-term memory, this effect was temporally limited in that the inhibitor gradually regained effectiveness over time. If memory strengthening was occurring as a result of the second retrieval, memory should have been resistant to ANI in all two retrieval conditions. Additionally, this theory cannot explain why a closely, but not more delayed retrieval event changed the effectiveness of protein synthesis inhibitors, since the strengthening is believed to occur over time. As a result, the change in the protein synthesis requirement in the present study likely cannot be attributed to a memory-strengthening interpretation.

One theory that could potentially explain the change in the protein synthesis requirement following the second closely timed retrieval is that of a change in memory lability or "destabilization". Memory lability following retrieval is thought to be regulated by NMDA receptor activity as a simultaneous blockade of NMDA receptors, and protein synthesis will prevent normal memory impairments that results from protein synthesis inhibition (Bem Mamou et al. 2006; Wang et al. 2009). A single CS retrieval then activates NMDA receptors, which results in a temporary destabilization of the memory; however, it is unknown how a second retrieval event given during this destabilization phase affects the lability of the memory. Downstream from NMDA receptors very little is known about the mechanisms that regulate this destabilization process, though there is evidence that it signals increases in proteasome-dependent protein degradation (Jarome et al. 2011). Recently, evidence has begun accumulating suggesting that changes in AMPAR phosphorylation and composition not only regulate the unique "reconsolidation-update" effect (Monfils et al. 2009; Clem and Huganir 2010), but also contribute to a temporary synaptic depotentiation following retrieval (Rao-Ruiz et al. 2011). In the latter, blocking these changes in AMPAR composition following retrieval did not impair memory, but did prevent memory updating. Collectively, these studies suggest that it is possible then that memory destabilization may be regulated by changes in AMPAR phosphorylation and composition following retrieval. In the present study, the second retrieval rapidly altered the phosphorylation state of GluR1, an effect that is likely dependent on increased NMDA receptor and calcineurin acivity (Ehlers 2000; Snyder et al. 2003). This suggests that the second retrieval may have altered the labile state of the memory through its alterations in GluR1 phosphorylation. Future studies should examine the specific pathway that regulates this dephosphorylation of GluR1 and whether it is critical for altering the protein synthesis requirement during the reconsolidation process.

If the alterations in GluR1 following the second of two closely timed retrievals does reflect a change in memory destabilization, then it seems unclear how the present results relate to the recently reported reconsolidation-update effect that uses a similar behavioral paradigm (Monfils et al. 2009; Clem and Huganir 2010). In the reconsolidation-update effect, the existing fear memory becomes weakened or erased as a result of an isolated CS retrieval being given prior to extinction training, and this memory weakening likely does rely on destabilization of the existing memory trace. While our multiple retrieval procedure is sim- ilar to that of the reconsolidation-update effect, the primary difference remains that the latter requires significantly more CS presentations to observe the memory weakening effect. As demonstrated in our study, simply giving two CS presentation spaced $1 \mathrm{~h}$ apart is not sufficient to induce memory erasure, evident by the strong behavior performance during the long-term memory test. This indicates that the two paradigms, while likely related due to the reconsolidation component, may rely on significantly different molecular processes in the amygdala. Thus, it is likely that the molecular mechanisms that mediate the reconsolidation-update effect are different from those that are involved in normal memory reconsolidation, which is what appeared to be altered in the present study. For example, retrieval has been shown to increase levels of GluR2 in hippocampal synapses, resulting in increased synaptic transmission (Rao-Ruiz et al. 2011). However, the reconsolidation-update effect is associated with a loss of CP-AMPARs and a reduction in synaptic transmission (Clem and Huganir 2010), supporting that the reconsolidation-update effect is memory erasure rather than updating. Thus, the end result of normal memory retrieval and the reconsolidation-update procedure is dramatically different at both the molecular and behavioral levels. It is possible though that the multiple-retrieval effect observed in the present study may influence the molecular processes that underlie the reconsolidation-update effect. Consistent with this, the rapid dephosphorylation of GluR1 in the present study has been associated with AMPAR endocytosis in vitro (Ehlers 2000). It is possible that in the reconsolidation-update effect the first CS of the extinction session rapidly dephosphorylates GluR1 receptors that were phosphorylated following the isolated CS retrieval, and the subsequent CS presentations during extinction then facilitate the removal of AMPARs from the synapse. Future research will need to examine this in more detail.

In conclusion, the present study found that the requirement for protein synthesis is altered following the second of two closely timed retrieval events. This altered protein synthesis requirement is not related to a change in Zif268 protein expression, but correlates with a rapid and persistent dephosphorylation of GluR1(Ser845) receptors at amygdala synapses. Considering accumulating evidence for the role of AMPA receptor dynamics in memory lability and updating, these specific changes to GluR1(Ser845) phosphorylation suggest a change in the labile state of the memory, reversing the effectiveness of the memory to protein synthesis inhibitors. These results provide the first evidence that the precise timing of subsequent retrieval events can alter the reconsolidation process occurring at amygdala synapses that were initiated by the first retrieval event, and that this process may be related to the temporally restricted changes in AMPAR dynamics present in the amygdala after fear memory acquisition and retrieval.

\section{Materials and Methods}

\section{Subjects}

Male Long-Evans rats were obtained for this experiment; nine animals were excluded due to misplaced or dislodged cannulae. All rats were housed individually in stainless-steel cages, and were free to access water and rat chow throughout the experiment. The colony was maintained on a 14:10 h light:dark cycle. All procedures were approved by the University of Wisconsin-Milwaukee institutional animal care and use committee, and carried out in accordance with the NIH guidelines for using animals in experimental procedures.

\section{Surgery}

Animals were handled for several days before surgery. Rats that underwent surgery were implanted with bilateral cannulas aimed 
at the amygdala (anteroposterior $[\mathrm{AP}],-2.8$; lateral $[\mathrm{L}], \pm 5.0$; ventral $[\mathrm{V}],-7.2)$ Coordinates were chosen based on a rat brain atlas (Paxinos and Watson 1998). Before surgery, animals were anesthetized with intraperitoneal injections of ketamine $\mathrm{HCl}$ (100 mg/kg body weight) and sodium pentobarbital $(2.5 \mathrm{mg} /$ $\mathrm{kg} / \mathrm{rat}$ ). The cannulae were anchored to the skull using stainlesssteel screws and acrylic cement. Obturators (33 gauge) were inserted into the guide cannulae to prevent blockage.

After completion of testing, animals were sacrificed with an intraperitoneal injection of sodium pentobarbital $(100 \mathrm{mg} / \mathrm{kg})$. Animals were transcardially perfused with saline followed by $10 \%$ buffered formalin solution. Heads, with cannulas intact, were placed in a $10 \%$ formalin solution for at least $24 \mathrm{~h}$. The brains were then extracted from the skull and placed in a 20\% sucrose formalin solution until they were ready to section. Frozen sections $(40 \mu \mathrm{m})$ were collected throughout the amygdala, mounted on slides, and stained with cresyl violet. Injection sites were then determined with the aid of a rat brain atlas (Paxinos and Watson 1998).

\section{Drugs}

In all cases where infusions were given, rats received bilateral infusions $(0.5 \mu \mathrm{L} /$ side) into the amygdala over $60 \mathrm{sec}$. The injection cannulae, which were cut to extend $\sim 0.5 \mathrm{~mm}$ beyond the guide cannulae, remained in place for an additional $90 \mathrm{sec}$ to ensure diffusion. Rats were returned to their home cages after infusions. ANI $(125 \mu \mathrm{g} / \mu \mathrm{L}$; Sigma) was dissolved in HCL and diluted with artificial cerebrospinal fluid (ACSF). A small amount of $\mathrm{NaOH}$ was added to bring the $\mathrm{pH}$ to $\sim 7.4$.

\section{Apparatus}

Fear conditioning took place in four identical observation chambers $(28 \times 20.5 \times 1 \mathrm{~cm})$ constructed of Plexiglas and stainless steel. The floor of each chamber was composed of stainless-steel rods spaced $1.5 \mathrm{~cm}$ apart through which foot shock could be delivered, and each chamber was illuminated by a $7.5 \mathrm{~W}$ white light bulb. Ventilation fans provided a constant background noise of $\sim 60 \mathrm{~dB}$. Testing to the auditory cue took place in a separate set of chambers that had floors made of Plexiglas; fans provided a background noise of $\sim 58 \mathrm{~dB}$. All chambers were housed in sound-attenuating boxes. The training chambers were cleaned with a 5\% ammonium hydroxide solution before each set of animals, while the boxes where auditory testing took place were cleaned with a $2 \%$ acetic acid solution.

\section{Behavioral procedures}

One week after surgery, animals were habituated to the handling and injection procedure. To habituate the animal to the microinjection procedure, each rat was restrained in a towel for several minutes, the obturators were removed, and the scalp was cleaned. During this time, the infusion pump to be used during the experiment was activated to habituate the animals to the sound it produces. After this was complete, the obturators were replaced and the animal was returned to its home cage. This was repeated once a day for $3 \mathrm{~d}$.

Training involved a 6-min baseline followed by four white noise $(72 \mathrm{~dB} ; 10 \mathrm{sec})$ shock $(1 \mathrm{~mA} / 1 \mathrm{sec})$ pairings separated by a 90 -sec intertrial interval. After a 4 -min postshock period, animals were removed from the training context (Context A). Memory retrieval involved placing the animals in a shifted environment (Context B) and after a 6-min baseline, the animals were provided with a 32-sec nonreinforced presentation of the white noise that was paired with shock during training. After a 28 -sec post-CS period, the animals were removed from the shifted context. In cases where animals received two retrieval events, they were brought back to the same shifted context and given a second retrieval session that also consisted of a 6-min baseline followed by a 32-sec nonreinforced presentation of the white noise that was paired with shock during training. All animals were removed $28 \mathrm{sec}$ after the end of the CS period. For the drug infusion experiments, ani- mals were given infusions immediately following the end of their final retrieval session. The animals were removed from the chamber and immediately brought into an adjacent room where they received the infusions of ANI or ACSF into the amygdala. Twenty-four hours after the drug infusion, animals were tested to the white noise for $5 \mathrm{~min}$ after a 6 -min baseline period. For quantitative protein experiments, animals were sacrificed at various times following retrieval, brains removed, flash-frozen, and prepared as described below.

\section{Whole cell and synaptosomal membrane preparation}

Amygdala tissue was dissected out by blocking the brain in a rat brain matrix (Harvard Apparatus) and making a single coronal cut at the anterior tip of the amygdala and one at the posterior end of the amygdala. Both sides of the whole amygdala were dissected out from the blocked tissue by making a cut along the external capsule and a diagonal cut along the optic tract. For whole cell lysates, the tissue sample was homogenized in buffer (all in $100 \mathrm{~mL}$ DDH20; $0.605 \mathrm{~g}$ Tris- $\mathrm{HCl}, 0.25 \mathrm{~g}$ sodium deoxycholate, $0.876 \mathrm{~g} \mathrm{NaCl}, 0.038 \mathrm{~g}$ EDTA, $0.0042 \mathrm{~g} \mathrm{NaF}, 1 \mu \mathrm{g} / \mathrm{mL}$ PMSF, $1 \mu \mathrm{g} / \mathrm{mL}$ leupeptin, $1 \mu \mathrm{g} / \mathrm{mL}$ aprotinin, $10 \mathrm{~mL}$ 10\% SDS, $1 \mathrm{mM}$ sodium orthovanadate) and immediately placed on dry ice. Samples were stored at $-80^{\circ} \mathrm{C}$ until needed. Samples were thawed and then centrifuged at $4000 \mathrm{rpm}$ for $20 \mathrm{~min}$; the supernatant was removed and measured using a Bradford protein assay kit (BioRad).

Crude synaptosomal membrane fractions were obtained as described previously with a small scale modification (Dunah and Standaert 2001; Ehlers 2003; Lee et al. 2008; Jarome et al. 2011). Briefly, samples were homogenized in TEVP with 320 $\mathrm{mM}$ sucrose and centrifuged at $1000 \mathrm{~g}$ for $10 \mathrm{~min}, 4^{\circ} \mathrm{C}$. The supernatant was collected and centrifuged at $10,000 \mathrm{~g}$ for $10 \mathrm{~min}, 4^{\circ} \mathrm{C}$. The resulting pellet was denatured in Lysis buffer (all in $100 \mathrm{~mL}$ DDH20; $0.605 \mathrm{~g}$ Tris- $\mathrm{HCl}, 0.25 \mathrm{~g}$ sodium deoxycholate, $0.876 \mathrm{~g}$ $\mathrm{NaCl}, 1 \mu \mathrm{g} / \mathrm{mL}$ PMSF, $1 \mu \mathrm{g} / \mathrm{mL}$ leupeptin, $1 \mu \mathrm{g} / \mathrm{mL}$ aprotinin, $10 \mathrm{~mL} 10 \% \mathrm{SDS}$ ) and centrifuged at $15,000 \mathrm{~g}$ for $5 \mathrm{~min}, 4^{\circ} \mathrm{C}$. The supernatant was collected and measured using a Bradford protein assay kit (BioRad).

\section{Western blotting}

Rats were exposed to the standard fear conditioning and memory retrieval procedures as described above. Separate groups of animals were used for Zif268 and both GluR1 expression patterns. Brains were removed and immediately put on dry ice and stored in a $-80^{\circ} \mathrm{C}$ freezer before dissection. For experiments 2 and 3 (Figs. 2,3$)$, protein samples (50 $\mu \mathrm{g}$ of whole cell, $10 \mu \mathrm{g}$ of synaptic) were normalized and loaded on 7.5\%-9\% SDS-polyacrylamide gel. (PAGE). Proteins were transferred from the gel to a membrane using a semidry transfer apparatus (Bio-Rad). Membranes were incubated in blocking buffer for $1 \mathrm{~h}$ and then incubated overnight at $4^{\circ} \mathrm{C}$ in primary antibody for Zif268, $\beta$-actin (all 1:1000; Cell Signaling) phosphorylated GluR1/Ser845 or total GluR1 (both 1:1000; Chemicon). After primary antibody exposure, the membranes were incubated in secondary antibody (dilution range 1:2000-1:5000; Upstate Biotechnology anti-rabbit) for 60-90 min. Membranes were washed thoroughly, placed in a chemiluminescence solution for $3 \mathrm{~min}$ (Santa Cruz Biotechnology), and exposed to autoradiographic film (Hyperfilm MP). For experiment 4 (Fig. 4), protein samples $(10 \mu \mathrm{g})$ were normalized and loaded on 7.5\% TGX gels, run through SDS-PAGE, and transferred using a Turbo Transfer system (Biorad). Membranes were then blocked and exposed to primary antibody as described above, followed by incubation in secondary antibody (dilution 1:20,000) for 60 min. Membranes were washed thoroughly, placed in enhanced chemiluminescence solution (Supersignal West Dura, Thermo) for $5 \mathrm{~min}$, and images captured using a camera-based system (GBOX Chemi XT-4, Syngene). Images were taken and densitometry was performed using NIH Image J. Mean optical densities were then statistically analyzed using a one-way ANOVA and Fisher's least significant difference (LSD) post hoc tests. 


\section{Acknowledgments}

We thank Wendy Ruenzel for technical assistance. This work was supported by National Institutes of Health grants MH088125 (T.J.J.) and MH069558, MH060668 (F.J.H.).

\section{References}

Bailey DJ, Kim JJ, Sun W, Thompson RF, Helmstetter FJ. 1999. Acquisition of fear conditioning in rats requires the synthesis of mRNA in the amygdala. Behav Neurosci 113: 276-282.

Ben Mamou C, Gamache K, Nader K. 2006. NMDA receptors are critical for unleashing consolidated auditory fear memories. Nat Neurosci 9: $1237-1239$

Boccia M, Freudenthal R, Blake M, de la Fuente V, Acosta G, Baratti C, Romano A. 2007. Activation of hippocampal nuclear factor-kB by retrieval is required for memory reconsolidation. J Neurosci $\mathbf{2 7}$ 13436-13445.

Clem RL, Huganir RL. 2010. Calcium-permeable AMPA receptor dynamics mediate fear memory erasure. Science 330: 1108-1112.

Dunah AW, Standaert DG. 2001. Dopamine D1-dependent receptor trafficking of striatal NMDA glutamate receptors to the postsynaptic membrane. I Neurosci 21: 5546-5548.

Duvarci S, Nader K, LeDoux JE. 2005. Activation of extracellular signal-regulated kinase-mitogen-activated protein kinase cascade in the amygdala is required for memory reconsolidation of auditory fear conditioning. Eur J Neuroscie 21: 283-289.

Ehlers MD. 2000. Reinsertion or degradation of AMPA receptors determined by activity-dependent endocytic sorting. Neuron 28: 511-525.

Ehlers MD. 2003. Activity levels control postsynaptic composition and signaling via the ubiquitin-proteasome system. Nat Neurosci 6: $231-242$.

Fanselow MS, LeDoux JE. 1999. Why we think plasticity underlying pavlovian fear conditioning occurs in the basolateral amygdala. Neuron 23: $229-232$.

Hall J, Thomas KL, Everitt BJ. 2001. Cellular imaging of Zif268 expression in the hippocampus and amygdala during contextual and cued fear memory retrieval: Selective activation of hippocampal CA1 neurons during the recall of contextual memories. J Neurosci 21: 2186-2193.

He K, Song L, Cummings LW, Goldman J, Huganir RL, Lee HK. 2009. Stabilization of $\mathrm{Ca}+$-permeable AMPA receptors at perisynaptic sites by GluR1-S845 phoshphorylation. Proc Natl Acad Sci 106: 20033-20038.

Inda MC, Muravieva EV, Alberini CM. 2011. Memory retrieval and the passage of time: From reconsolidation and strengthening to memory extinction. J Neurosci 31:1635-1643.

Jarome TJ, Werner CT, Kwapis JL, Helmstetter FJ. 2011. Activity dependent protein degradation is critical for the formation and stability of fear memories in the amygdala. PLoS One 6: e24349. doi: 10.1371/ journal.pone.0024349.
Kim J, Song B, Hong I, Kim J, Lee J, Park S, Eom JY, Lee CJ, Lee S, Choi S. 2010. Reactivation of fear memory renders consolidated amygdala synapses labile. J Neurosci 30: 9631-9640.

Lee JLC. 2008. Memory reconsolidation mediates the strengthening of memory by additional learning. Nat Neurosci 11: 1264-1266.

Lee JL, Everitt BJ, Thomas KL. 2004. Independent cellular processes for hippocampal memory consolidation and reconsolidation. Science 304: $839-843$.

Lee S-H, Choi JH, Lee N, Lee H-R, Kim J-I, Yu N-K, Choi S-L, Lee S-H, Kim H, Kaang B-K. 2008. Synaptic protein degradation underlies destabilization of retrieved fear memory. Science 319: 1253-1256.

McGaugh JL. 2000. Memory-a century of consolidation. Science 287: 248-251.

Merlo E, Freudenthal R, Maldonado H, Romano A. 2005. Activation of the transcription factor $\mathrm{NF}_{-\mathrm{K}} \mathrm{B}$ by retrieval is required for long-term memory reconsolidation. Learn Mem 12: 23-29.

Monfils M-H, Cowansage KK, Klann E, LeDoux JE. 2009. Extinction-reconsolidation boundaries: Key to persist attenuation of fear memories. Science 324: 951-955.

Nader K, Schafe GE, LeDoux JE. 2000. Fear memories require protein synthesis in the amygdala for reconsolidation following retrieval. Nature 406: 722-726.

Parsons RG, Gafford GM, Helmstetter FJ. 2006a. Translational control via the mammalian target of rapamycin pathway is critical for the formation and stability of long-term fear memory in amygdala neurons. J Neurosci 26: 12977-12983.

Parsons RG, Gafford GM, Baruch DE, Riedner BA, Helmstetter FJ. 2006b. Long-term stability of fear memory depends on the synthesis of protein but not mRNA in the amygdala. Eur J Neurosci 23: 1853-1859.

Paxinos G, Watson C. 1998. The rat brain in stereotaxic coordinates, 4 th ed. Academic Press, San Diego, CA.

Rao-Ruiz P, Rotaru DC, van der Loo RJ, Mansvelder HD, Stiedl O, Smit AB, Spijker S. 2011. Retrieval-specific endocytosis of GluA2-AMPARs underlies adaptive reconsolidation of contextual fear. Nat Neurosci 14: $1302-1308$.

Schafe GE, LeDoux JE. 2000. Memory consolidation of auditory pavlovian fear conditioning requires protein synthesis and protein kinase $\mathrm{A}$ in the amygdala. J Neurosci 20: $1-5$.

Snyder GL, Galdi S, Fienberg AA, Allen P, Nairn AC, Greengard P. 2003. Regulation of AMPA receptor dephosphorylation by glutamate receptor agonists. Neuropharmacology 45: 703-713.

Tronson NC, Taylor JR. 2007. Molecular Mechanisms of Reconsolidation. Nat Rev Neurosci 8: 1-14.

Tronson NC, Wiseman SL, Olausson P, Taylor JR. 2006. Bidirectional behavioral plasticity of memory reconsolidation depends upon amygdalar protein kinase A. Nat Neurosci 9: 167-169.

Wang SH, de Oliveria Alvares L, Nader K. 2009. Cellular and systems mechanisms of memory strength as a constraint on auditory fear reconsolidation. Nat Neurosci 12: 905-912.

Received November 20, 2011; accepted in revised form April 27, 2012. 


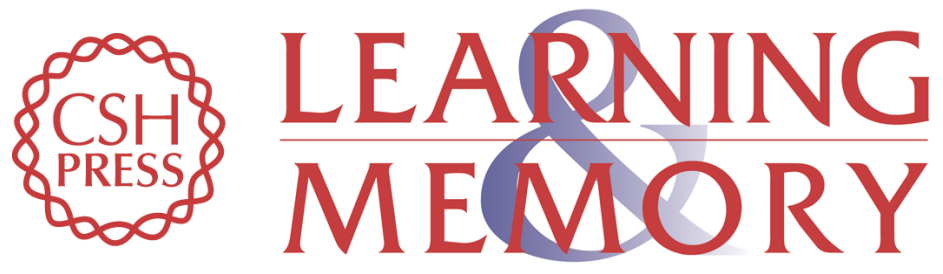

\section{The timing of multiple retrieval events can alter GluR1 phosphorylation and the requirement for protein synthesis in fear memory reconsolidation}

Timothy J. Jarome, Janine L. Kwapis, Craig T. Werner, et al.

Learn. Mem. 2012, 19:

Access the most recent version at doi:10.1101/lm.024901.111

Supplemental http://learnmem.cshlp.org/content/suppl/2012/06/19/19.7.300.DC1

Material

References This article cites 29 articles, 14 of which can be accessed free at: http://learnmem.cshlp.org/content/19/7/300.full.html\#ref-list-1

License

Email Alerting Receive free email alerts when new articles cite this article - sign up in the box at the Service top right corner of the article or click here. 